\title{
Intersurgeon variability in long-term outcomes after transatrial repair of tetralogy of Fallot: 25 years' experience with 675 patients
}

\author{
Yves d'Udekem, MD, PhD, ${ }^{\text {a,b,c }}$ John C. Galati, BSc, PhD, ${ }^{\text {d,e }}$ Igor E. Konstantinov, MD, PhD, , a,c \\ Michael H. Cheung, MB, ChB, ${ }^{\mathrm{f}}$ and Christian P. Brizard, MD ${ }^{\mathrm{a}, \mathrm{b}, \mathrm{c}}$
}

\begin{abstract}
Objective: To compare the long-term reoperation rates among surgeons performing transatrial repair of tetralogy of Fallot.
\end{abstract}

\begin{abstract}
Methods: The data set of 675 patients undergoing transatrial repair of tetralogy of Fallot at 1 institution from 1980 to 2005 was analyzed for intersurgeon differences in the reoperation rates.

Results: A follow-up period $>15$ years was available for 5 surgeons, allowing for comparison (541 patients; $>80$ patients/surgeon). The reintervention rate at 10 years varied from $8.8 \%$ (95\% confidence interval [CI], $5.3 \%-14.5 \%$ ) to $26.7 \%(95 \% \mathrm{CI}, 14.9 \%-44.9 \%$; hazard ratio, $3.4 ; P=.001)$. The procedures of 1 surgeon resulted in a reoperation rate of $10.5 \%$ at 20 years $(95 \% \mathrm{CI}, 5.4 \%-25.3 \%)$. The type of reoperation required varied among the surgeons. One surgeon had had no reoperations for pulmonary artery stenosis. Of the 5 surgeons, 2 (surgeons 2 and 5) had equivalent overall 10-year reoperation rates $(24.1 \%, 95 \% \mathrm{CI}, 12.9 \%-42.3 \%$; vs $26.7 \%, 95 \% \mathrm{CI}$, $14.9 \%-44.9 \% ; P=.32$ ). Surgeon 5 had reoperation almost exclusively for right ventricular outflow tract obstruction $(20.6 \% ; 95 \% \mathrm{CI}, 12.4 \%-33.1 \%)$ and surgeon 2 for right ventricular dilation $(17.4 \%$; $95 \% \mathrm{CI}$, $7.8 \%-36.3 \%$ ). None of the patients treated by surgeon 5 required implantation of a valved conduit.
\end{abstract}

Conclusions: An analysis of the reoperation rate during the long-term follow-up of transatrial repair of tetralogy of Fallot identified variability in the outcomes among 5 surgeons. The analysis of these differences suggested that an optimal amount of opening of the right ventricular outflow tract can lead to a decreased reintervention rate. The analysis of intersurgeon variability in outcomes should be encouraged, because it will lead to improvements in cardiac surgery outcomes. (J Thorac Cardiovasc Surg 2014;147:880-8)

In a large proportion of the patients undergoing tetralogy of Fallot repair, relief of the right ventricular (RV) outflow tract (RVOT) obstruction necessitates a transannular incision and patching of the hinge points of the pulmonary valve. $^{1-3}$ It has been estimated that 20 years after undergoing Fallot repair, $30 \%$ to $40 \%$ of patients could require the implantation of a valved conduit in their RVOT because the created pulmonary insufficiency has resulted in RV dilatation. ${ }^{4-6}$

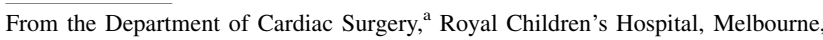
Australia; Murdoch Childrens Research Institute, ${ }^{\mathrm{b}}$ Melbourne, Australia; Department of Pediatrics, ${ }^{\mathrm{c}}$ The University of Melbourne, Melbourne, Australia; Clinical Epidemiology and Biostatistical Unit, ${ }^{\mathrm{d}}$ Murdoch Childrens Research Institute, Melbourne, Australia; Department of Mathematics and Statistics, ${ }^{\mathrm{e}}$ La Trobe University, Melbourne, Australia; Department of Cardiology, ${ }^{\mathrm{f}}$ Royal Children's Hospital, Melbourne, Australia

The present research project was supported by the Victorian Government's Operational Infrastructure Support Program.

Disclosures: Dr d'Udekem is a Career Development Fellow of the National Heart Foundation of Australia (CR 10M 5339). All other authors have nothing to disclose with regard to commercial support.

Read at the 93rd Annual Meeting of The American Association for Thoracic Surgery, Minneapolis, Minnesota, May 4-8, 2013.

Received for publication May 1, 2013; revisions received Oct 11, 2013; accepted for publication Nov 11, 2013; available ahead of print Dec 13, 2013.

Address for reprints: Yves d'Udekem, MD, PhD, Department of Cardiac Surgery, Royal Children's Hospital, Flemington Rd, Parkville, Melbourne, Victoria 3052, Australia (E-mail: yves.dudekem@rch.org.au).

$0022-5223 / \$ 36.00$

Copyright (c) 2014 by The American Association for Thoracic Surgery

http://dx.doi.org/10.1016/j.jtcvs.2013.11.010
Two main surgical techniques are available for repair of tetralogy of Fallot: the transventricular technique, after which the ventricular septal defect is closed through the ventriculotomy; and the transatrial technique, after which the ventricular septal defect is closed through the tricuspid valve. ${ }^{2,7}$ It has long been suspected that patients would have a reduced incidence of late RV dilatation if their RVOT remained slightly restrictive after repair. ${ }^{1,3,8}$ The recent publication of a long-term follow-up study and an animal experiment have seemed to confirm this hypothesis. ${ }^{9,10}$ It has been postulated that patients undergoing repair with the transatrial technique would have a smaller incision on the RVOT and, therefore, a reduced incidence of RV dilatation requiring valvulation of the RVOT. ${ }^{1,8}$

We have recently reported the long-term outcomes of all patients treated with a transatrial repair at the Royal Children's Hospital, Melbourne, with a policy of repair delayed beyond the neonatal period. ${ }^{11}$ With the use of this technique and policy, we observed hospital mortality of $1 \%$ and only 2 sudden deaths of 668 survivors of the repair. The veracity of these data was ascertained in the National Death Registries. Only $15 \%$ of our patients required the implantation of a valved conduit in their RVOT in the 20 years after repair.

We believed that under the generic term "transatrial repair," the surgeons of our team would vary in the methods used to perform this operation, in particular, in the amount of opening of the RVOT. We hypothesized that patients 

Abbreviations and Acronyms
CI = confidence interval
$\mathrm{HR}=$ hazard ratio
MRI = magnetic resonance imaging
$\mathrm{RV}=$ right ventricular
$\mathrm{RVOT}=$ right ventricular outflow tract

treated by surgeons who would proceed with a larger opening would have a greater risk of reoperation for RV dilatation and those treated by surgeons practicing more restrictive opening of the RVOT would have a greater risk of reoperation for RVOT obstruction (Figure 1). To determine the effect of this potential variation in practice, we analyzed the intersurgeon variability in long-term outcomes after transatrial repair of tetralogy of Fallot performed within the same center.

\section{METHODS}

The local hospital ethics committee approved the design of the present study. The data set of a previous analysis of outcomes after transatrial repair performed at the Royal Children's Hospital was reanalyzed for differences in late outcomes among surgeons, a parameter that had not been previously investigated. ${ }^{11}$ The exclusion criteria were an associated atrioventricular septal defect, pulmonary atresia, and double outlet right ventricle. After 1981, transatrial repair became the sole operative technique used in our center. From 1980 to 2005, 675 consecutive patients underwent transatrial repair of tetralogy of Fallot at our center. Their outcomes data were recently collected. Seven patients could no longer be located; the mean follow-up of the remaining population was $11.7 \pm 6$ years.

\section{Mode of Referral}

During the study period, the Royal Children's Hospital has remained the sole institution in Victoria, Australia, offering pediatric cardiac surgery, providing this service for Victoria, South Australia, Tasmania, Northern Territory, and, up to the 1990s, in Western Australia. During the study period, acceptance for surgery and decision-making followed the same rules. All cases referred for surgery by individual cardiologists were discussed at the Royal Children's Hospital case conference, in which all cardiologists and surgeons present made decisions concerning acceptance of surgery, type of surgery recommended, and timing of surgery. Cases were allocated among the surgeons of the team by the head of the department. Reoperations were preferably addressed to the surgeon who had performed the initial operation if the surgeon was still working at the center. Decisions concerning reinterventions were all discussed during the same case conference. No set guidelines were used to determine the need for reintervention. In recent years, magnetic resonance imaging (MRI)-determined RV volumes have been used as the predominant criteria for reintervention indicated for RV dilatation. Because of the unreliability of the results of interventional catheterization for pulmonary artery origin stenosis and the lower threshold to perform these noninvasive procedures, only surgical procedures were considered as adverse outcomes.

Reoperations for congenital heart disease have all been performed at a limited number of centers in Australia, all of which were contacted to gather the follow-up data for the patients.

\section{Policy and Surgical Technique}

The center maintained a constant policy during the study period. All patients had undergone repair after a minimum of 4 months of age.
Patients presenting with persistent cyanosis, spells, or small pulmonary arteries before that age received a systemicopulmonary shunt. This policy resulted in the prerepair palliation with shunting of 220 of the 675 patients $(33 \%)$. The median age at repair was 2 years (interquartile range, 15 months to 3.4 years) from 1980 to 1987 and 10 months (interquartile range, 7-14) from 2000 to 2005 . The details of the surgical technique of transatrial repair have been previously described. ${ }^{7} \mathrm{RV}$ pressure measurements were not routinely performed at our center.

\section{Statistical Analysis}

Of the 675 patients, 7 did not survive to successful Fallot repair and 8 were excluded because of a requirement for a RV-pulmonary artery conduit at repair. The remaining 660 patients had undergone surgery by 13 different surgeons, who had treated a total of $1,1,1,5,17,17,19,39$, $81,84,85,127$, and 164 patients. The surgical outcomes for the 5 surgeons who had treated $>80$ patients each were compared for 2 separate endpoints. The first was the risk of requiring a first reintervention for 3 indications: RV dilatation, RVOT obstruction, and pulmonary origin stenosis. The second was the risk of undergoing implantation of a valved conduit in the RVOT at any point during the follow-up period. Kaplan-Meier analysis was used to assess the freedom from reintervention for the various indications. An examination of the risk factors for reintervention had been previously performed in our overall cohort. ${ }^{11}$ Direct comparisons of the outcomes among the surgeons, with adjustment for the primary confounders of age at repair and previous palliation, were conducted using Cox regression analysis. The postrepair RVOT gradient was not considered as a confounder, because it was judged to be a consequence of the surgical technique. The results of risk analyses accounting for the competing risk of mortality were also examined; however, these were essentially the same as those obtained by Cox regression analysis (owing to the small number of late deaths after Fallot repair). To facilitate the comparison of the patient characteristics treated by each of the 5 surgeons, the patients treated by the 8 surgeons who each had had $<80$ repairs were combined into a single reference group. We considered the distribution of RVOT gradients immediately after Fallot repair for each surgeon to provide an indication of the amount of opening of the RVOT. Differences in the average gradient among the surgeons were tested using a nonparametric test of equality of the median. The relationship between the risk of subsequent reoperation and the RVOT gradient after Fallot repair was examined using fractional polynomial regression analysis.

\section{RESULTS}

Five surgeons had accumulated enough outcomes data to allow a comparative analysis. These 5 surgeons had treated 541 patients, with an accumulated mean follow-up period of $11.9 \pm 6.3$ years. Surgeons 1 and 4 were operating during the same era as surgeons 2 and 5. The comparison of the patient characteristics treated by these 5 surgeons is displayed in Table 1.

For the 5 surgeons compared, the 90 reinterventions were classified according to their main indication as follows: RV dilatation $(\mathrm{n}=29)$, RVOT obstruction $(\mathrm{n}=44)$, and pulmonary artery origin stenosis $(\mathrm{n}=17)$. A comparison of the freedom from intervention for each of these indications for each of the 5 surgeons is displayed in Figure 2.

The 10-year rate of first reintervention for any of these 3 indications varied from $8.8 \%$ (95\% confidence interval [CI], $5.3 \%-14.5 \%)$ to $26.7 \%$ (95\% CI, $14.9 \%-44.9 \%$ ). This variation corresponded to a univariate hazard ratio 


\section{Small outflow tract incision}

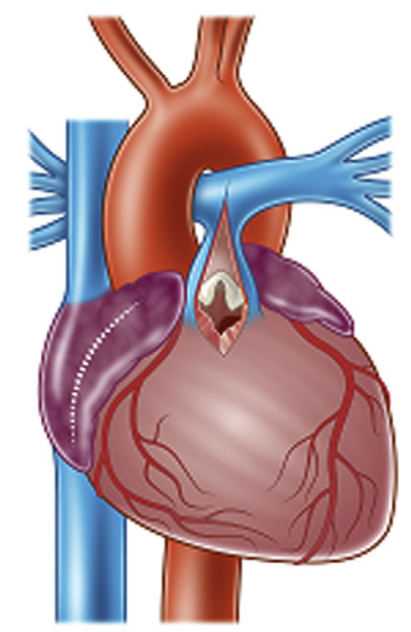

\section{Large outflow tract incision}

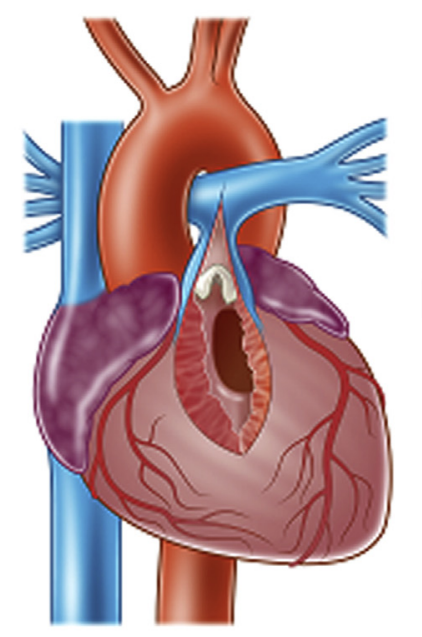

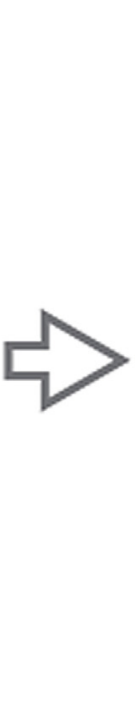

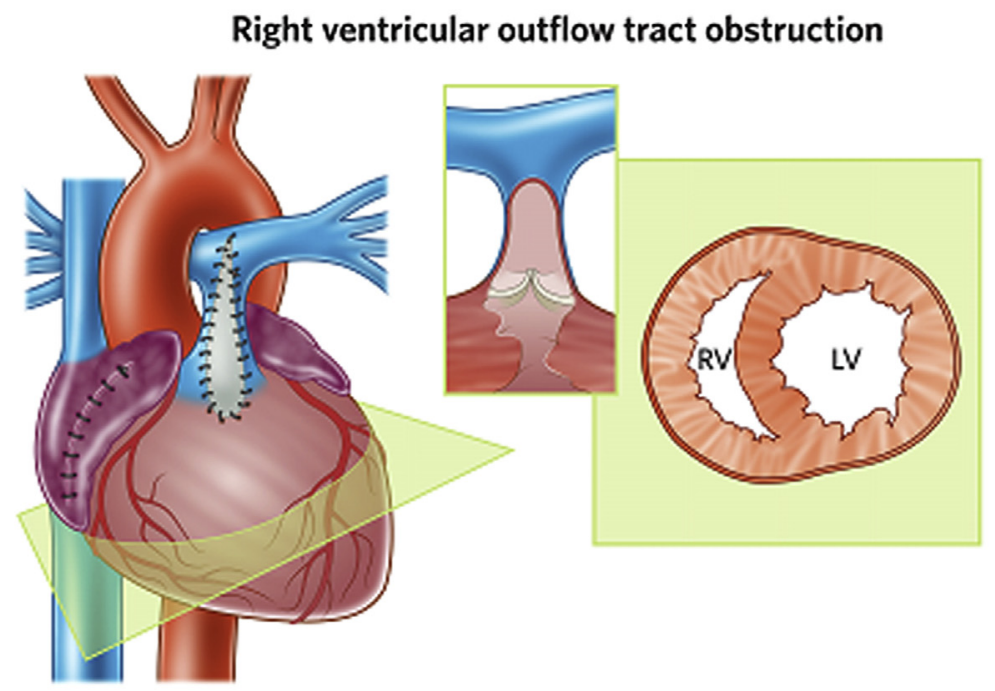

Right ventricular dilatation
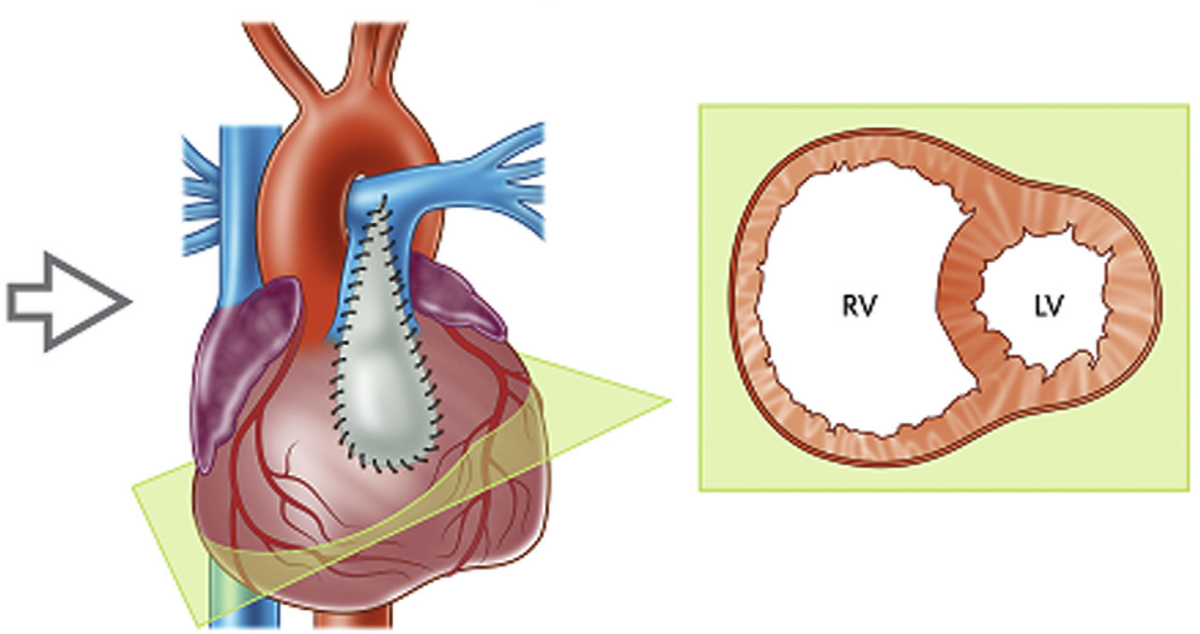

FIGURE 1. A smaller incision of the right ventricular outflow tract led to reoperation for right ventricular outflow tract obstruction and a larger incision to reoperation for right ventricular dilatation. $R V$, Right ventricle; $L V$, left ventricle.

[HR] of $3.4(95 \% \mathrm{CI}, 1.6-7.1 ; P=.001)$, comparing the surgeon with the greatest estimated proportion of reinterventions at 10 years (surgeon 5) and the surgeon with the lowest (surgeon 1). At 20 years after Fallot repair, the lowest rate of reoperation had been achieved by surgeon 4 , whose procedures resulted in a reoperation rate of $10.5 \%$ at 20 years $(95 \% \mathrm{CI}, 5.4 \%-25.3 \%)$.

For all the 13 surgeons combined, the independent risk factors predicting the occurrence of the 3 studied reoperations were the postrepair RVOT gradient (HR, 1.3; 95\% CI, 1.2-1.5; $P<.001$ ), younger age at repair (HR, 0.7; 95\% CI, 0.5-0.9; $P=.003$ ), and previous palliation (HR, $2.1 ; 95 \% \mathrm{CI}, 1.3-3.2 ; P=.001)$. The other parameters analyzed in the model that were not independent predictors were patch type (treated autologous pericardium, untreated autologous pericardium, and other type vs no patch), patch of the pulmonary artery origin, and use of a transannular incision. Eleven of the 17 patients requiring a first reoperation for pulmonary artery origin stenosis had had previous patching of the pulmonary artery origin. Similar results applied when the data were restricted to the group of patients treated by the 5 particular surgeons compared in the present study (HR, 1.3 and $P<.001$ for the postrepair RVOT gradient; HR, 0.6 and $P=.001$ for younger age at repair; and HR, 2.2 and $P=.002$ for previous palliation). The results of risk-adjusted analysis confirmed the range of variation among reoperation rates of the surgeons. After adjustment for patient age at repair and previous palliation, the estimated relative reoperation rate between the surgeons with the highest and lowest estimated proportion of reoperations at 10 years was an HR of 2.7 (95\% CI, 1.3-5.6; $P=.011$ ).

Of the 5 surgeons, 2 (surgeons 1 and 4 ) had a similar rate and pattern of reoperations. Their 20 -year reoperation rate 
TABLE 1. Patient characteristics stratified by surgeon

\begin{tabular}{|c|c|c|c|c|c|c|}
\hline \multirow[b]{2}{*}{ Characteristic } & \multicolumn{6}{|c|}{ Surgeon } \\
\hline & Reference group & 1 & 2 & 3 & 4 & 5 \\
\hline Patients (n) & 118 & 164 & 127 & 85 & 81 & 84 \\
\hline Female gender $(\%)$ & 40 & 41 & 35 & 42 & 38 & 29 \\
\hline Years of repair (first to last) & $1980-2004$ & 1981-1994 & $1995-2004$ & 1983-1998 & 1980-1992 & $1996-2005$ \\
\hline Age at repair (y) & $1.2(0.8-1.7)$ & $1.4(0.8-2.7)$ & $1.0(0.7-1.3)$ & $1.1(0.9-1.4)$ & $1.7(1.1-3.2)$ & $0.9(0.5-1.2)$ \\
\hline Hospital mortality (\%) & 2.5 & 0.6 & 0.8 & 0 & 0 & 0 \\
\hline Late mortality $(\%)$ & 1.7 & 1.8 & 1.6 & 2.4 & 3.7 & 0 \\
\hline Previous palliation $(\%)$ & 33 & 32 & 24 & 34 & 41 & 27 \\
\hline Monocusp (\%) & 11 & 5 & 14 & 8 & 4 & 5 \\
\hline Transannular incision $(\%)$ & 63 & 49 & 72 & 68 & 58 & 81 \\
\hline Patch of PA origin $(\%)$ & 25 & 16 & 17 & 13 & 19 & 19 \\
\hline $\begin{array}{l}\text { RVOT gradient after ToF repair } \\
\quad(\mathrm{mm} \mathrm{Hg})(P \text { value })\end{array}$ & $0(0-16)$ & $0(0-6.8 ; P=.001)$ & $9(0-19 ; P=.063)$ & $0(0-19 ; P=.027)$ & $0(0-0 ; P=.001)$ & $0(0-28 ; P=.15)$ \\
\hline \multicolumn{7}{|l|}{ Patch type } \\
\hline None & 17 & 32 & 6 & 11 & 22 & 8 \\
\hline AP untreated & 39 & 67 & 91 & 66 & 75 & 25 \\
\hline AP treated & 16 & 0 & 0 & 3 & 0 & 64 \\
\hline Non-AP & 28 & 1 & 3 & 20 & 3 & 3 \\
\hline \multicolumn{7}{|l|}{ Reoperation } \\
\hline $\begin{array}{l}\text { Total RVOT obstruction, RV } \\
\text { dilatation, and PA stenosis }\end{array}$ & $19(16)$ & $25(15)$ & $17(13)$ & $20(24)$ & $10(12)$ & $18(21)$ \\
\hline RVOT obstruction & $8(7)$ & $14(9)$ & $3(2)$ & $8(9)$ & $4(5)$ & $15(18)$ \\
\hline RV dilatation & $8(7)$ & $8(5)$ & $10(8)$ & $8(9)$ & $1(1)$ & $2(2)$ \\
\hline PA stenosis & $3(3)$ & $3(2)$ & $4(3)$ & $4(5)$ & $5(6)$ & $1(1)$ \\
\hline Valved-conduit implantation & $6(5)$ & $10(6)$ & $8(6)$ & $10(12)$ & $5(6)$ & $1(1)$ \\
\hline
\end{tabular}

Data presented as \%, median (interquartile range), or n (\%). PA, Pulmonary artery; RVOT, right ventricular outflow tract; ToF, tetralogy of Fallot; $A P$, autologous pericardium; $R V$, right ventricular.

was $10.5 \%(95 \%$ CI, $5.4 \%-25.3 \%)$ versus $16.7 \%(95 \%$ CI, $10.9 \%-20.1 \%$; HR, 0.8; 95\% CI, 0.4-1.7; $P=.56)$.

The type of reoperation required varied among the
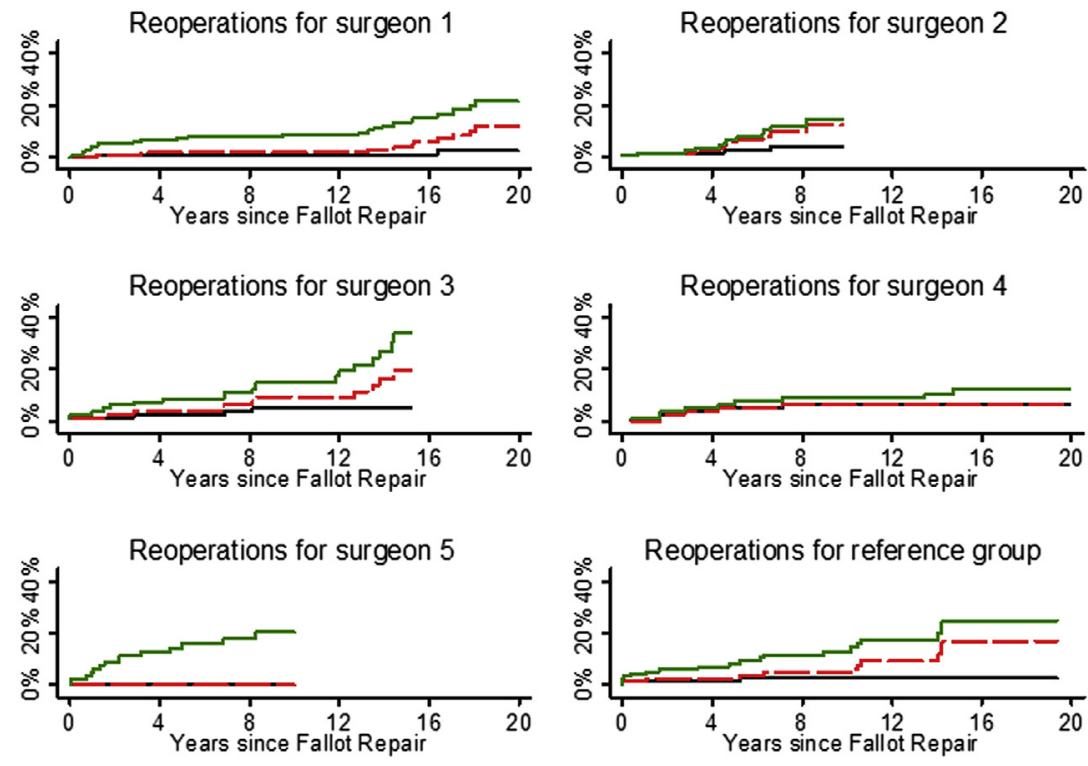

Proportion of reoperations for PA Stenosis (Black); RV Dilatation (Black to Red); RVOT Obstruction (Red to Green)

FIGURE 2. Freedom from the first reintervention for the 5 surgeons who had performed $>80$ procedures and for the reference group of 8 surgeons for the indications of right ventricular obstruction, right ventricular dilatation, and origin of the pulmonary artery stenosis. Black indicates proportion of reoperations for pulmonary artery stenosis; black to red, proportion of reoperations for right ventricular dilatation; red to green, proportion of reoperations for right ventricular outflow tract obstruction. 

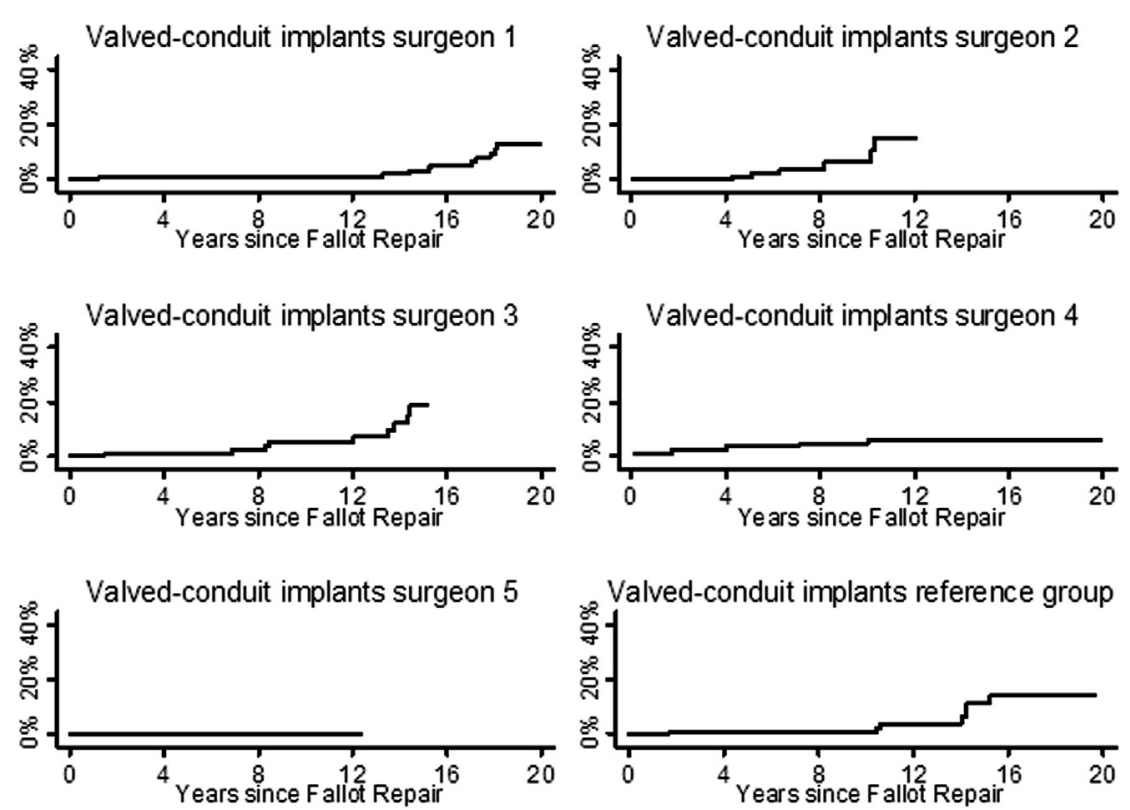

FIGURE 3. Freedom from implantation of a valved conduit in the right ventricular outflow tract for the 5 surgeons who had performed $>80$ procedures and the reference group of 8 surgeons.

(95\% CI, 2.7\%-14.4\%). Of the 5 surgeons, 2 (surgeons 2 and 5) had equivalent overall 10 -year reoperation rates $(24.1 \%$; 95\% CI, $12.9 \%-42.3 \%$; vs $26.7 \%$; $95 \%$ CI, $14.9 \%-44.9 \%$; HR, $1.4 ; 95 \%$ CI, 0.7-2.9; $P=.32)]$. However, surgeon 5 had performed reoperation for RVOT obstruction almost exclusively $(20.6 \%$; 95\% CI, $12.4 \%$ $33.1 \%$ ) and surgeon 2 almost exclusively for RV dilatation $(17.4 \% ; 95 \%$ CI, $7.8 \%-36.3 \%)$.

Of the 541 patients treated by the 5 surgeons studied, 34 required implantation of a valved conduit in their RVOT at any stage during their follow-up. Of the 36 patients who had undergone reoperation for RVOT obstruction before any

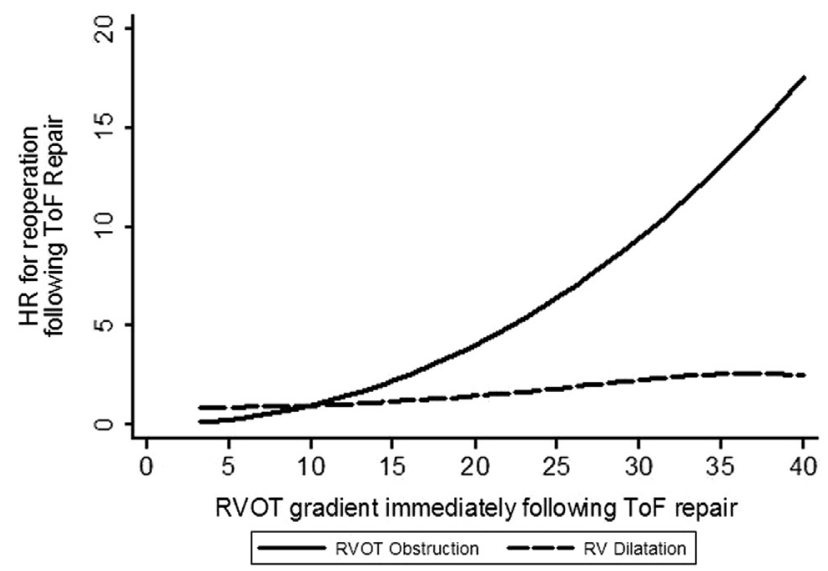

FIGURE 4. Relative hazard for reoperation for right ventricular outflow tract $(R V O T)$ obstruction and right ventricular $(R V)$ dilatation as a function of the RVOT gradient before hospital discharge after transatrial repair for tetralogy of Fallot $(T o F)$. reoperation for RV dilatation, pulmonary artery origin stenosis, or implantation of a valved conduit, only 4 patients required subsequent implantation of a valved conduit. The comparison of freedom from valved conduit implantation in the RVOT among these 5 surgeons is displayed in Figure 3. The estimated proportion of reoperations at 10 years varied from $0 \%$ (surgeon 5 ) to $10.6 \%(95 \% \mathrm{CI}$, $3.9 \%-27 \%$; surgeon 2). Estimates at 20 years were available only for surgeons 1 and 4 and were 13\% $(95 \%$ CI, 7.1\%-22.9\%) and 6.3\% (95\% CI, 2.7\%-14.6\%), respectively.

For the 5 surgeons, the risk factors predicting implantation of a valved conduit were younger age at repair (HR, 0.6; 95\% CI, 0.4-0.9; $P=.033$ ) and previous palliation (HR, 2.1; 95\% CI, 1.0-4.4; $P=.046$ ). The other parameters analyzed in the model that were not independent predictors were the construction of a monocusp in the outflow tract and the use of a transannular patch.

Differences were noted in the reoperation rates among the 5 surgeons. After adjustment for patient age at repair and previous palliation, the relative rate of valve implantation for surgeons 2 to 5 compared with surgeon 1 was as follows: HR, 9.0 (95\% CI, 2.6-31; $P<.001)$ for surgeon 2; HR, 3.2 (95\% CI, 1.2-8.5; $P=.023$ ) for surgeon 3 ; HR, $1.1(95 \% \mathrm{CI}, 0.4-3.2 ; P=.91)$ for surgeon 4 ; and HR, $1.4(95 \%$ CI, 0.2-12; $P=.79)$ for surgeon 5. Although these results point to real differences in outcomes among the surgeons regarding freedom from reoperation involving valve implantation, some caution is required, given the relatively small number of reoperations performed (34 for all 5 surgeons). 
The relationship between the RVOT gradient after Fallot repair and the risk of subsequent reoperation for RVOT obstruction and RV dilatation is illustrated in Figure 4. Surgeons varied in the spread of the RVOT gradient after repair (Table 1$)$, with both surgeon $1(P=.001)$ and surgeon $4(P=.001)$ having a substantially lower residual gradient compared with the reference group of surgeons.

\section{DISCUSSION}

Only limited examples have been published of comparisons of the long-term outcomes among individual surgeons. The rare examples reported in recent studies have been restricted to survival after rectal surgery and the rate of incontinence after radical prostatectomy. ${ }^{12}$ The investigation of variations in outcomes among surgeons after pediatric cardiac surgery has been limited to the study of differences in hospital mortality for the most severe conditions and medicolegal studies driven by public health departments. ${ }^{13-18}$ We believed that the study of the long-term outcomes after tetralogy of Fallot repair would be the ideal subset to analyze the intersurgeon variability in outcomes. Patients with tetralogy of Fallot will be affected by varying degrees of obstruction of their outflow tract; however, the association with other cardiac or extracardiac anomalies has been rare. They are, therefore, a relatively homogenous group of patients with an occurrence of adverse events (reoperations) high enough to allow for analysis. Our recruitment during the study period was consistently based on an entire population, eliminating potential referral bias. We used the same standardized technique and the same strategy of early palliation of cyanosed patients during the entire study period. We hypothesized that the main difference among the surgeons of our team would be the amount of RVOT opening and that the type of reoperation performed would vary accordingly. We assumed that the patients treated by surgeons favoring a large RVOT opening would require more reintervention for RV dilatation and those treated by surgeons favoring a more restrictive opening would face a greater risk of reintervention for RVOT obstruction.

We believe that our comparison of patient outcomes after Fallot repair performed by various surgeons is more informative of the best method to perfect this repair than a report of the best outcomes by individuals or a group. One could have suspected that differences in outcomes would exist among surgeons, although this subject seems somewhat taboo. All reoperation rates reported were better than the published rates of reoperation after Fallot repair. The present analysis, however, found that 1 surgeon could achieve a $10 \%$ rate of reoperation, well below the current expectations. One could wonder whether this remarkable historical result could still be reproduced today. The median age at repair of 1.7 years for his patients was older than the current usual age at repair in most centers worldwide.
Although it might seem inappropriate or impractical to perform Fallot repair later than 1 year of age, this low reoperation rate could constitute an argument to complete the repair later or at least after the neonatal age. It could also be argued that patients treated in an early era may have been subjected to less stringent criteria for reoperation, leading to a lower rate of reoperation. We do not believe that patients from the earlier era missed reoperation because of premature death, because we found that only 2 patients had died of sudden death in our entire series, a finding confirmed by an analysis of the National Death Registries. ${ }^{11}$ In Australia, all patients with congenital heart disease are followed up by a restricted number of teams and hospitals, and all these hospital databases were searched for these patients. We, therefore, believe that the ultimate 20 -year rate of reoperation reported is valid, although reoperations would have occurred at a later stage in patients treated in earlier era.

The most striking finding of the present study was that the main reason for reoperation varied among the surgeons, pointing to a difference in technique within the same generic term of "transatrial repair." In particular, surgeons 2 and 5, who were operating in the contemporary period, had a similar reoperation rate, but 1 performed reoperations exclusively for RV dilatation and the other exclusively for RVOT obstruction. The patients treated by the latter surgeon (exclusively for RVOT obstruction) did not require implantation of a valved conduit, at least not during the study period. This finding seems to confirm the hypothesis that a smaller opening of the RVOT is an effective measure to prevent the deleterious consequences of longstanding pulmonary regurgitation. At this stage, it would seem that reoperation for RV obstruction does not expose patients to a later increased risk of reintervention for valve implantation. For this surgeon, this strategy resulted in the reoperation of one fifth of his patients within 10 years. Whether this rate of reoperation was justified is debatable, if only $10 \%$ of the patients might require a valved conduit implantation in the 20 years after repair with a larger incision. Whether avoiding at all costs the implantation of a valved conduit justifies the greater rate of early reoperation for $\mathrm{RV}$ obstruction remains speculative. It is also possible that the patients with restrictive outflow tracts will have a limited exercise capacity. It is certain that all efforts should be made to prevent the need for implantation of a valved conduit in the late outcomes after Fallot repair. Our study results have pointed to an ideal amount of opening of the RVOT in Fallot repair, paving the way for the development of strategies to achieve this goal.

\section{Study Limitations}

Ideally, we would like to have available for each patient the pre- and postoperative MRI measurements of the RVOT and RV volumes. However, consistent accumulation 
of these data for a 25 -year period would be impossible to obtain. The surgeons examined in the present study were not all working in contemporary eras, limiting the validity of the intersurgeon comparison. In particular, patients treated in an earlier era were older at their repair and had more frequently undergone previous palliation. Although the analyses were adjusted for these differences, the potential for differences in unmeasured confounders to have influenced the results remained. Additionally, it would not be impossible that the indications for reoperation varied slightly during the study period. The main findings of the present study should not have been affected by this limitation. Patients treated in the early era were, in the contemporary period, followed by the same teams as those treated later and were, therefore, subjected to the same indication criteria. Also, the main variations among the surgeons were observed for surgeons 2 and 5, who were operating during the same era.

The strengths of the study were the quality of our follow-up, that Australian patients with congenital heart disease are treated only at a limited number of centers, and that the decision for reintervention for all patients was determined by teams closely collaborating rather than by individual surgeons.

\section{CONCLUSIONS}

The analysis of the reoperation rate during the long-term follow-up of transatrial repair of tetralogy of Fallot identified variability in the outcomes among surgeons. The observed differences in the postrepair RVOT gradient among surgeons suggest that variability could exist in the amount of opening of the RVOT among surgeons. If so, this might explain the observed intersurgeon variability in late outcomes. If correct, an optimal amount of opening for the RVOT might exist that would lead to a minimal rate of reintervention. The analysis of intersurgeon variability in outcomes should be encouraged, because it will lead to improvements in the outcomes after cardiac surgery.

The authors would like to thank Mr Bill Reid for professional preparation of the illustrations.

\section{References}

1. Sfyridis PG, Kirvassilis GV, Papagiannis JK, Avramidis DP, Ieromonachos CG, Zavaropoulos PN, et al. Preservation of right ventricular structure and function following transatrial-transpulmonary repair of tetralogy of Fallot. Eur J Cardiothorac Surg. 2013;43:336-42.

2. Al Habib HF, Jacobs JP, Mavroudis C, Tchervenkov CI, O’Brien SM, Mohammadi S, et al. Contemporary patterns of management of tetralogy of Fallot: data from the Society of Thoracic Surgeons database. Ann Thorac Surg. 2010;90:813-20.

3. Bové T, François K, Van De Kerckhove K, Panzer J, De Groote K, De Wolf D, et al. Assessment of a right-ventricular infundibulum-sparing approach in transatrial-transpulmonary repair of tetralogy of Fallot. Eur J Cardiothorac Surg. 2012;41:126-33.

4. d'Udekem Y, Ovaert C, Grandjean F, Gerin V, Cailteux M, Shango-Lody P, et al. Tetralogy of Fallot: transannular and right ventricular patching equally affect late functional status. Circulation. 2000;102(19 Suppl 3):III116-22.
5. Hickey EJ, Veldtman G, Bradley TJ, Gengsakul A, Manlhiot C, Williams WG, et al. Late risk of outcomes for adults with repaired tetralogy of Fallot from an inception cohort spanning four decades. Eur J Cardiothorac Surg. 2009;35: 156-64; discussion 164.

6. Lindberg HL, Saatvedt K, Seem E, Hoel T, Birkeland S. Single-center 50 years' experience with surgical management of tetralogy of Fallot. Eur J Cardiothorac Surg. 2011;40:538-42.

7. Karl TR, Sano S, Pornviliwan S, Mee RB. Tetralogy of Fallot: favorable outcome of nonneonatal transatrial, transpulmonary repair. Ann Thorac Surg. 1992;54: 903-7.

8. d'Udekem d'Acoz Y, Pasquet A, Lebreux L, Ovaert C, Mascart F, Robert A, et al. Does right ventricular outflow tract damage play a role in the genesis of late right ventricular dilatation after tetralogy of Fallot repair? Ann Thorac Surg. 2003;76: 555-61.

9. van der Hulst AE, Hylkema MG, Vliegen HW, Delgado V, Hazekamp MG, Rijlaarsdam MEB, et al. Mild residual pulmonary stenosis in tetralogy of Fallot reduces risk of pulmonary valve replacement. Ann Thorac Surg. 2012;94: 2077-82.

10. Bové T, Bouchez S, De Hert S, Wouters P, De Somer F, Devos D, et al. Acute and chronic effects of dysfunction of right ventricular outflow tract components on right ventricular performance in a porcine model: implications for primary repair of tetralogy of Fallot. J Am Coll Cardiol. 2012;60:64-71.

11. d'Udekem Y, Galati JC, Rolley GJ, Konstantinov IE, Weintraub RG, Grigg LE, et al. Low risk of pulmonary valve implantation after a policy of transatrial repair of tetralogy of Fallot delayed beyond the neonatal period: the Melbourne experience over 25 years. J Am Coll Cardiol. Epub 2013 Oct 30 .

12. Birbeck KF, Macklin CP, Tiffin NJ, Parsons W, Dixon MF, Mapstone NP, et al. Rates of circumferential resection margin involvement vary between surgeons and predict outcomes in rectal cancer surgery. Ann Surg. 2002; 235:449-57.

13. Pasquali SK, Jacobs JP, He X, Hornik CP, Jaquiss RDB, Jacobs ML, et al. The complex relationship between center volume and outcome in patients undergoing the Norwood operation. Ann Thorac Surg. 2012;93:1556-62.

14. Welke KF, O'Brien SM, Peterson ED, Ungerleider RM, Jacobs ML, Jacobs JP. The complex relationship between pediatric cardiac surgical case volumes and mortality rates in a national clinical database. J Thorac Cardiovasc Surg. 2009; $137: 1133-40$.

15. Tabbutt S, Ghanayem N, Ravishankar C, Sleeper LA, Cooper DS, Frank DU, et al. Risk factors for hospital morbidity and mortality after the Norwood procedure: a report from the Pediatric Heart Network Single Ventricle Reconstruction trial. J Thorac Cardiovasc Surg. 2012;144:882-95.

16. Hirsch JC, Gurney JG, Donohue JE, Gebremariam A, Bove EL, Ohye RG. Hospital mortality for Norwood and arterial switch operations as a function of institutional volume. Pediatr Cardiol. 2007;29:713-7.

17. Spiegelhalter DJ. Mortality and volume of cases in paediatric cardiac surgery: retrospective study based on routinely collected data. BMJ. 2002;324: 261-3.

18. Aylin P, Alves B, Best N, Cook A, Elliott P, Evans SJ, et al. Comparison of UK paediatric cardiac surgical performance by analysis of routinely collected data 1984-96: was Bristol an outlier? Lancet. 2001;358:181-7.

\section{Discussion}

Dr Marshall Jacobs (Philadelphia, $P a$ ). This intriguing analysis was based on the premise that analyzing the variation in outcomes among individual surgeons who purport to be doing the same operation could lead to a better understanding of the essential features of the operation. In that respect, it is of general interest and specific interest. Specifically, surgical repair of tetralogy of Fallot is not a cure. The resultant physiology is not completely normal, and many patients will require interventions later in life.

Proponents of transatrial repair have postulated that it will result in a reduced incidence of $\mathrm{RV}$ dilatation requiring later implantation of a pulmonary valve. These results in Melbourne for $>3$ decades are truly outstanding, with probably the lowest 
rate of mortality in any series of operations for tetralogy of Fallot of this size. In this very large cohort, transannular patching was performed in $75 \%$ of the cases. At 15 and 25 years, only $9 \%$ and $15 \%$ had undergone implantation of a pulmonary valve, respectively. At 25 years, the overall freedom from reintervention was $25 \%$.

Twelve years ago, at a meeting of this Association, a report was presented of a series of patients who had undergone repair in infancy of tetralogy of Fallot using a transventricular approach. The presentation was discussed by an outstanding senior surgeon from Melbourne who had made the following, not quite excoriating, comment: "What worries me is that so little information is given about the right ventricles of these patients." Dr Roger Mee called for " ...objective data from echocardiograms and exercise testing."

Dr d'Udekem, in your report describing Melbourne's large consecutive transatrial repair cohort, you explained that pulmonary valve replacement was usually undertaken when severe pulmonary regurgitation was found in the presence of RV dilatation, RV dysfunction, or symptoms of exercise intolerance. Echocardiographic data at an average follow-up of 12 years showed that pulmonary regurgitation was estimated to be severe in $\geq 193$ patients and moderate in 96 patients. These numbers were far greater than the number who had undergone pulmonary valve implantation.

Your analysis of the variation in the rate of reoperation among surgeons is fascinating. One wonders, however, whether freedom from various types of reintervention is the best method to evaluate the effectiveness of an operative strategy. Also, does it adequately discriminate among the results achieved by the individual surgeons or is the rate of reoperation actually a minimal estimate of those patients with troubled right ventricles?

My first question is, would not the overall assessment and the specific differences among the individual surgeons' outcomes be even more informative if the analysis were based on objective data of the RV size and function, regurgitant fraction, and exercise capacity, rather than entirely on the rate of reoperation?

Dr d'Udekem. Thank you very much. I think that is a very excellent point. What we are concerned with is the functional capacity of these patients.

MRI data are very difficult to obtain. We do not have in Melbourne the research MRI facilities necessary to do a crosssectional study of our Fallot population. The echocardiographic data are subject, as you know, to subjectivity. It would be difficult to have a precise evaluation of RV function and RV volumes. However, we do have actually exercise studies for the patients from Victoria. I did not think to consider the difference among the surgeons, but I will promptly do that as soon as I am back. It is an excellent idea.

Dr Jacobs. Thank you. My second question relates to the analysis of variation in outcomes among the individual surgeons as a method of identifying the characteristics of an optimal operative procedure. The competing objectives of relieving outflow tract obstruction and minimizing the volume burden imposed by pulmonary insufficiency will be influenced by both the individual patient anatomy and the individual surgeon's technique. This suggests the possibility of a "sweet spot" at which one does enough resection through a minimal incision to relieve obstruction but does not cause severe pulmonary insufficiency. You pointed out that the surgeon with the lowest incidence of pulmonary valve replacement had a very high rate of patients requiring reintervention for right ventricular outflow tract obstruction. So, my second question is, has this study led you to an assessment of what would be an acceptable gradient to leave at the end of the operation? That is, where is the "sweet spot" between relief of obstruction and disruption of competence of the pulmonary valve? Another way of asking, is if you took the patients of surgeon 2 and surgeon 5 at late follow-up and had them exercise, which group would perform better, the group who had residual obstruction or the group who had had wide open regurgitation after their initial repair?

Dr d'Udekem. It is a very important point, and I would like to elaborate a little bit on this. The real answer is we do not know exactly what we have to do with the outflow tract of these patients. We know that RV dilatation is bad. You do not want to put a valved conduit in these patients, and once you place the first valved conduit, you start an eternal circle in which you are going to have to keep performing reoperations on these patients. When you study these patients with tetralogy of Fallot, they go through different stages in life. They are born with RV hypertrophy, they dilate, you put a conduit in them, the next reoperation will be for obstruction, they start becoming hypertrophic again, and what we do not know is at the end what kind of heart does it make? We need the 40-year perspective. Some of these patients we see have been coming back after 40 years with wrecked biventricular function, and if the origin of their dysfunction was the initial RV dilatation, we should perhaps avoid RV dilatation at all costs.

The old textbooks would tell you that it is bad to leave RV outflow tract obstruction, but that is no longer the case with the contemporary technique. We have presented, but not published, our results with patients left with residual obstructions $>40 \mathrm{~mm}$ $\mathrm{Hg}$. They have not died and they have been fairly asymptomatic, not by an exercise study, but they have been fairly asymptomatic. Thus, we do not know exactly whether we have to reoperate when they have RVOT obstruction.

Now, there is something that can help you. You have to look at the age, and I do not mean the age of the patient. I think you have to look at the age of the surgeon. Thus, if you are a senior surgeon or in the middle of your career, you can have as many reoperations for RVOT obstruction as you want-you are still going to keep your job. However, if you are a young surgeon and you are starting at a new place, I would recommend not having a $25 \%$ rate of reoperation at 5 to 10 years because I do not think you are going to look good. So, if you want to look better, if I can have my extra slide here, I can help you a little bit on how to look good, because we plotted the echocardiographic data before hospital discharge against the risk of reoperation, all reoperations and those for dilatation and for obstruction. You will find that the HR of reoperation was basically around 1 at a 15 to $20-\mathrm{mm} \mathrm{Hg}$ gradient. Again, I do not say that we needed to do these reoperations for RVOT obstruction. That was a historical series. These are the indications you will receive from your mainstream cardiologists. At a $30-\mathrm{mm} \mathrm{Hg}$ gradient, you will have a HR of 2, you have 
doubled the risk of reoperation, and at a 50-mm $\mathrm{Hg}$ gradient, you have quadrupled the risk of reoperation.

Dr Jacobs. Well, I think we learned a great deal from this interesting analysis. The concept itself is excellent, and I recommend your report to those who want to pursue this interesting topic. I hope in the future you will be able to analyze some physiologic data and perhaps data on the length of the outflow tract incision, which you speculated was important. Thank you.

Access to The Journal of Thoracic and Cardiovascular Surgery Online is reserved for print subscribers!

Full-text access to The Journal of Thoracic and Cardiovascular Surgery Online is available for all print subscribers. To activate your individual online subscription, please visit The Journal of Thoracic and Cardiovascular Surgery Online, point your browser to http://www.mosby.com/itcvs, follow the prompts to activate your online access, and follow the instructions. To activate your account, you will need your subscriber account number, which you can find on your mailing label (note: the number of digits in your subscriber account number varies from 6 to 10). See the example below in which the subscriber account number has been circled:

\section{Sample mailing label}

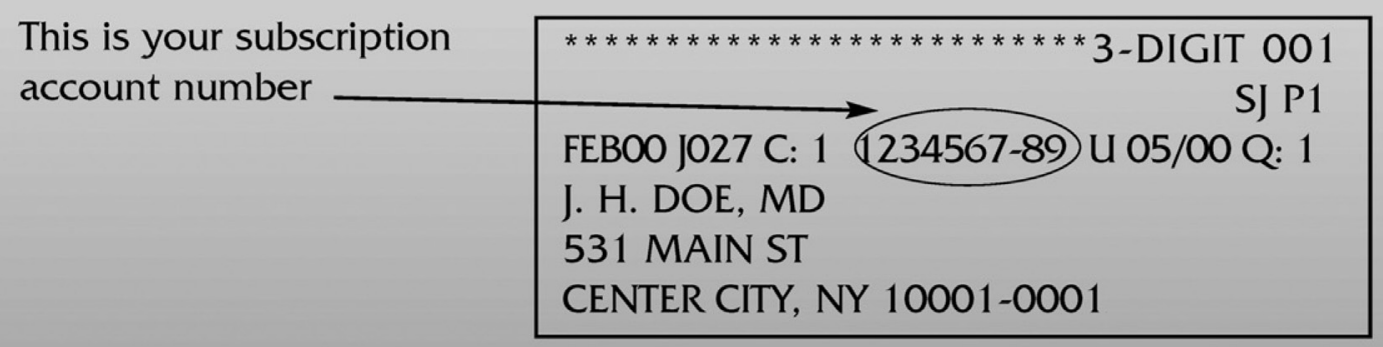

Personal subscriptions to The Journal of Thoracic and Cardiovascular Surgery Online are for individual use only and may not be transferred. Use of The Journal of Thoracic and Cardiovascular Surgery Online is subject to agreement to the terms and conditions as indicated online. 